\title{
Tooth loss in aggressive periodontitis patients: retrospective study with follow-up of 3 to 8 years
}

\author{
Ye-Sol Park, Young-Mi Chung, Seong-Nyum Jeong*
}

Department of Periodontology, Wonkwang University Daejeon Dental Hospital, Wonkwang University School of Dentistry, Daejeon, Korea

The purpose of this study was to assess the clinical outcomes of active periodontal therapy (APT) and supportive periodontal therapy (SPT) through loss of teeth in the Korean patients with aggressive periodontitis. The number of missing and residual teeth, probing pocket depth were examined in 33 patients diagnosed with aggressive periodontitis at the baseline and who had participated in APT and SPT for 3 years or more. A 20 and 3 teeth were lost during the APT and SPT, respectively. The mean tooth loss rate of 0.13 per patient and year. There was no significant statistical difference in clinical improvement between the smoker and non-smoker groups. Within the limitation of this study, APT combined with supportive therapy could decrease the risk of tooth loss in patients suffering from aggressive periodontitis.

Key Words: Aggressive periodontitis, Maintenance, Periodontal pocket, Tooth loss

(c) This is an open-access article distributed under the terms of the Creative Commons Attribution Non-Commercial License (http://creativecommons.org/licenses/by-nc/4.0) which permits unrestricted noncommercial use, distribution, and reproduction in any medium, provided the original work is properly cited.

\section{서 론}

급진성 치주염은 만성 치주염에 비하여 빠른 속도로 치주 조직의 부착상실과 치조골의 흡수가 진행되고 이로 인해 치아 상실의 위험을 증가시키는 파괴적 치주질환으로 알려져 있다 [1,2]. 급진성 치주염의 유병률은 인종과 지역에 따라 매우 다 양하며, 전 세계적으로 $0.1 \%-15 \%$ 범위까지 보고되어 있다[36]. 한국인의 경우 급진성 치주염의 유병률 연구가 매우 적으나 1987년 Leem 등[7]은 0.09\%로 보고한 바 있다. 성(gender)에 따른 질환의 발생률 차이에 대해서 아직까지 일관된 결론은 없 으나, 2005년 Susin과 Albandar [8]은 남녀 간에 차이가 없음을 보고한 바 있다.

급진성 치주염은 그 임상적 양상에 따라 국소적 형태와 전반 적 형태로 분류할 수 있다. 국소적 형태의 경우 구강 내 다른 부
위에 비해 전치부 및 제 1 대구치에서 부착소실이 주로 발생하며, 좌우 대칭적으로 나타나는 경우가 많다[9]. 국소적 형태로 시작 하여 전반적 형태로 진행하게 되는데, Mombelli 등[10]은 전반 적 형태의 급진성 치주염과 만성 치주염에서 치은연하 미생물 총에 차이가 거의 없음을 보고하였다.

현재까지 급진성 치주염 치료를 위한 방안으로는 만성 치주 염의 치료와 마찬가지로 비외과적 치주치료, 판막거상소파술 을 포함한 외과적 치주치료, 지속적인 유지치주치료 등이 제시 되었다[11-13]. 급진성 치주염 환자의 치아 유지에 대한 논란의 여지는 있으나 대부분 전통적인 치주치료를 통해 장기간 동안 안정적으로 유지됨이 보고되고 있다[14,15].

한국인에서 치주질환 치료에 대한 전문 진료 수요 중 상당수 의 환자가 급진성 치주염의 양상을 보이고 있고 비교적 젊은 연 령에 비해 심각한 수준으로 치주조직이 파괴된 상태로 대학병

Received August 24, 2018; Revised November 15, 2018; Accepted November 19, 2018

Corresponding author: Seong-Nyum Jeong, Department of Periodontology, Wonkwang University Daejeon Dental Hospital, Wonkwang University School of Dentistry, 77 Dunsan-ro, Seo-gu, Daejeon 35233, Korea.

Tel: +82-42-366-1141, Fax: +82-42-366-1115, E-mail: seongnyum@wonkwang.ac.kr

Copyright $\odot$ 2018, Oral Biology Research Institute 
원에 내원하는 상황으로 파악된다. 하지만 한국인에서 급진성 치주염의 유병률과 이 질환으로 인한 치주조직 파괴 수준 평가, 치료에 대한 반응에 관한 연구는 매우 부족한 실태이다.

따라서 본 연구의 목적은 원광대학교 대전치과병원 치주과 에 내원하여 3년 이상 추적 관찰된 급진성 치주염 환자를 대상 으로 적극적인 외과 및 비외과적 치주치료(active periodontal therapy, APT)와 유지치주치료(supportive periodontal therapy, SPT)의 효과를 치아상실을 통해 평가하는 것이었다.

\section{대상 및 방법}

\section{연구대상}

2008년부터 2016년까지 원광대학교 대전치과병원 치주과 에 내원하여 전반적 급진성 치주염으로 진단받고 치석제거 및 치근활택술 등 비외과적 치주치료, amoxicillin (Augmentin; Ilsung, Seoul, Korea)과 metronidazole (Flasinyl; CJ, Seoul, Korea)을 1주간 복합 처방하는 약물치료, 치주판막술 및 외과 적 재생술식 등을 포함한 APT 및 정기적 추적관찰 등을 포함한 $\mathrm{SPT}$ 에 3년 이상의 기간 동안 참여한 33명의 환자, 894개의 치 아를 대상으로, 후향적으로 평가하였다(Fig. 1-3).

급진성 치주염의 진단기준은 1999년 American Academy of Periodontology workshop에서 제시한 기준을 따랐으며(Table 1) [16], 추가적으로 1) 초진 시 연령이 40세 미만인 경우 2) 치
주질환 가족력이 있는 경우로 대상을 선정하였다. 이 연구는 원 광대학교 치과대학 연구윤리위원회의 승인을 받아 진행되었다 (승인번호: WKDIRB 20170904).

\section{임상검사}

모든 환자에 대해 초진 시 임상 치주검사 전에 전신병력 및 치 과병력, 치주질환의 가족력 여부에 대해 문답을 시행하였고, 전 신병력은 흡연 여부, 고혈압, 당뇨 유무와 심장, 신장, 간 질환 등으로 인한 수술병력 및 기타 기저질환 유무를 조사하였다. 이 중 흡연자는 급진성 치주염 진단 기준에 포함되지 않으므로 연

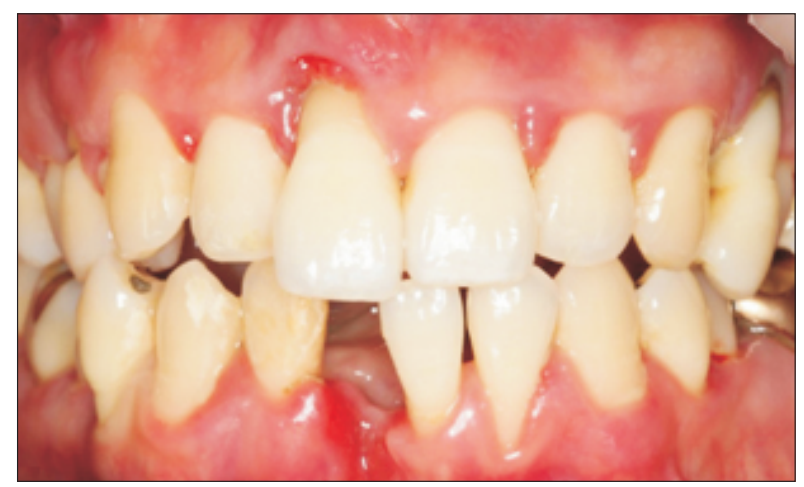

Fig. 2. Intraoral clinical photograph of the same aggressive periodontitis patient of Fig. 1. On the next day of the first visit, lower central incisor was removed spontaneously.
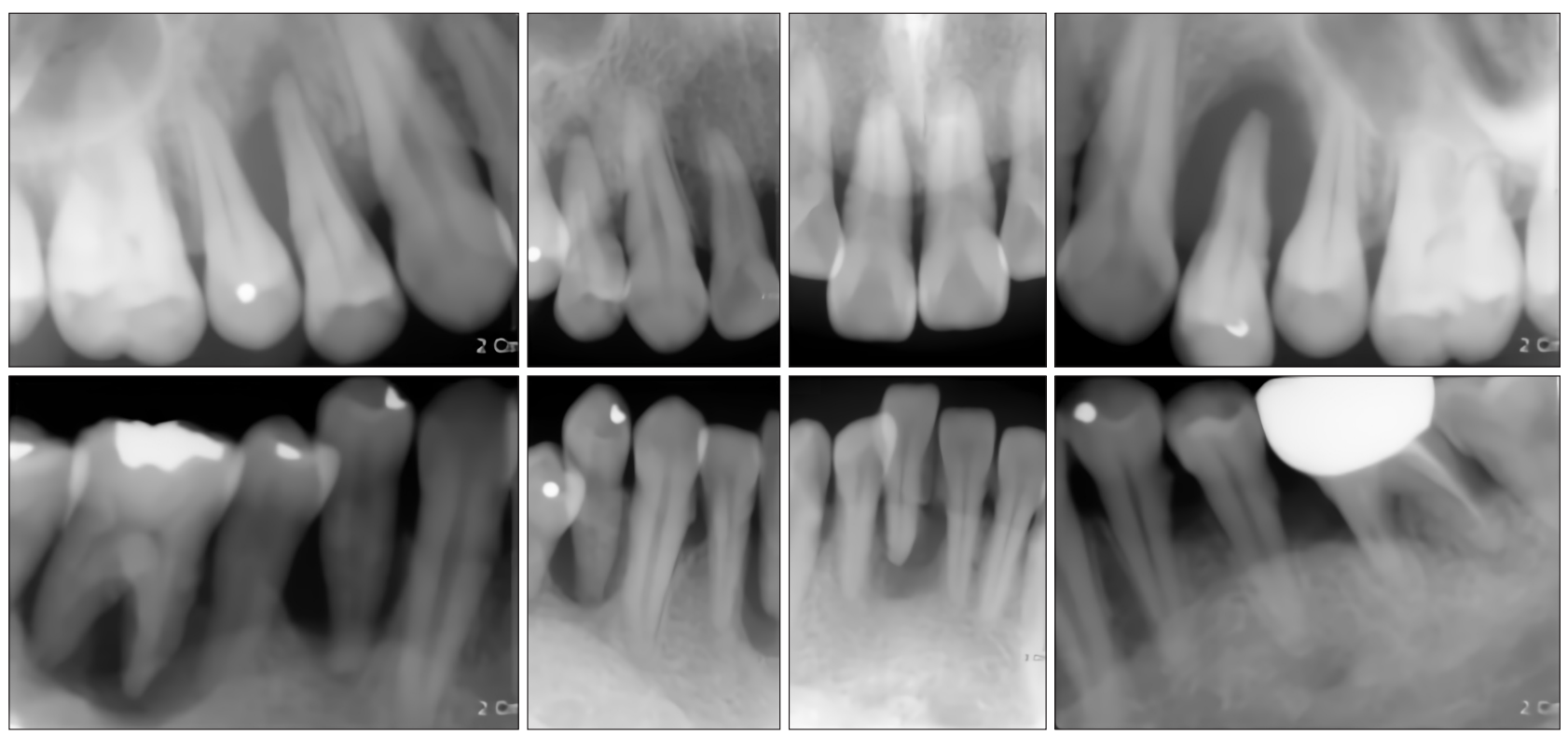

Fig. 1. Intraoral periapical radiographs of the 27 years old aggressive periodontitis patient. The mandibular right central incisor and fisrt molar, the maxillary left first premolar were about to be spontaneously exfoliated, and the alveolar bone of the other remaining teeth is also severely resorbed. The patient had a family history of severe periodontitis. 


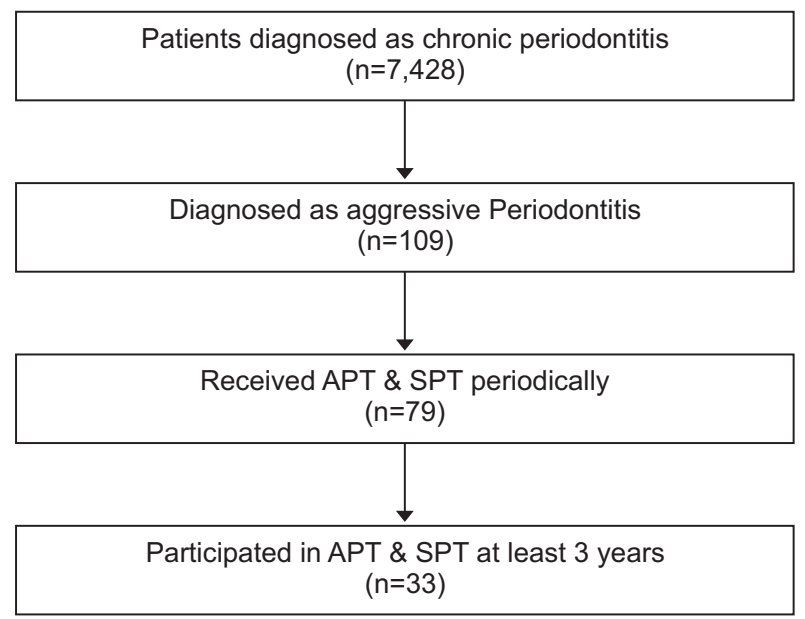

Fig. 3. Screening of patients. APT, active periodontal therapy; SPT, supportive periodontal therapy.

구대상자에서 배제하지 않았으나 추적관찰 시 흡연을 영향 요 인으로 고려하였고, 이 외 전신질환으로 인한 의과병력이 존재 하는 경우 진단 시 배제하여, 다른 전신질환에 이환되지 않은 환 자만을 급진성 치주염 환자로 진단하였다.

초진 시와 최종 관찰시점에서 잔존치아 수 및 상실치아 수, $\mathrm{APT} / \mathrm{SPT}$ 기간 동안 상실된 치아 수, 상 하악 중절치와 양측 제 1 대구치에서 탐침 치주낭 깊이를 측정하고 기록하였으며, 탐침 치주낭 측정은 유리치은 변연에서 치주낭 기저부까지 치주탐침 (PW; Hu Friedy Manufacturing Co., Chicago, IL, USA)을 사 용하였으며 설측 및 순측에서 각각 근심, 중앙, 원심으로 나누 어, 한 치아당 총 6부위를 측정하였다.

\section{통계분석}

통계적 분석을 위해 PASW Statistics ver. 18.0 software (IBM Co., Armonk, NY, USA)를 사용하여 independent t-test, Mann-Whitney test 로 유의성을 평가하였다.

\section{결 과}

2008년 1월부터 2016년 12월까지 본원에 내원한 치주염 환 자 총 7,537명 중에서 급진성 치주염으로 진단받은 환자는 109 명으로, $1.4 \%$ 의 발생빈도를 나타냈다(Table 2, Fig. 3). 남녀 성 (gender)에 의한 급진성 치주염 발생 빈도의 차이는 나타나지 않았다 $(p>0.05)$. 급진성 치주염으로 진단된 환자 109명 중에 서 치석제거 및 치근활택술, 치주판막수술을 포함하는 적극적 치주치료(APT)를 받고 이후 정기적인 유지관리치료(SPT)를 받 은 79명의 환자가 일차 연구 대상이 되었으며, 이들 중에서 3년
Table 1. Diagnostic criteria based on the 1999 AAP classification of periodontal diseases

\begin{tabular}{l} 
Criteria \\
\hline Localized aggressive periodontitis \\
Rapid attachment and bone loss in otherwise healthy patients \\
First molar-incisor presentation with no more than two other \\
teeth affected \\
At least two permanent teeth affected where at least 1 is \\
a first molar \\
LCAL $\geq 4$ mm at the affected sites \\
Generalized aggressive periodontitis \\
Rapid attachment and bone loss in otherwise healthy patients \\
Generalized interproximal attachment loss affecting at least three \\
teeth other than first molars and incisors \\
LCAL $\geq 4$ mm at the affected sites
\end{tabular}

AAP, American Academy of Periodontology; LCAL, lifetime cumulative attachment loss.

Table 2. Frequency of subjects by gender

\begin{tabular}{lccc}
\hline Gender & $\begin{array}{c}\text { Chronic } \\
\text { periodontitis }\end{array}$ & $\begin{array}{c}\text { Aggressive } \\
\text { periodontitis }\end{array}$ & Total \\
\hline Female & $2,873(99.0)$ & $30(1.0)$ & $2,903(100.0)$ \\
Male & $4,555(98.3)$ & $79(1.7)$ & $4,634(100.0)$ \\
Total & $7,428(98.6)$ & $109(1.4)$ & $7,537(100.0)$ \\
\hline
\end{tabular}

Values are presented as number (\%).

No statistically significant difference by gender $(p=0.317)$.

이상의 기간 동안 참여한 33명의 급진성 치주염 환자가 최종 연 구대상이 되었다(Fig. 3).

33 명 연구대상자의 평균연령은 초진 시 32.3 세로, 남성 24 명, 여성 9명으로 구성되었으며, 평균 $\mathrm{APT}$ 및 $\mathrm{SPT}$ 참여 기간은 평 균 5.56년으로 나타났다(중앙값 5.50; 3.0-8.5 (년) 범위). 흡연 자는 13 명(남성 12 명, 여성 1명), 비흡연자 및 금연 5년 이상 유 지 환자는 20 명(남성 12 명, 여성 8 명)으로 나타났다.

초진 시 전체 연구대상에서 총 30 개의 치아, 평균 인당 0.91 개의 치아가 상실된 상태로 내원하였으며, APT 기간 중에는 총 20 개, SPT 기간 중에는 총 3 개의 치아가 상실되어. 치아 상실률 은 관찰 기간 동안 환자당 연간 평균 0.13 개로 나타났다. 흡연 자 군에서 비흡연자 군에 비하여 평균 상실률이 높았으나, 두 집 단간에 통계적으로 유의한 차이는 발견되지 않았다 $(p=0.062)$ (Table 3).

초진 시 전체 연구대상 평균 치주낭 깊이는 $6.95 \mathrm{~mm}$ 였고 
Ye-Sol Park, et al.

Table 3. Tooth mortality rate

\begin{tabular}{lccc}
\hline \multicolumn{1}{c}{ Tooth loss } & $\begin{array}{c}\text { Smoker } \\
(\mathbf{n = 1 3})\end{array}$ & $\begin{array}{c}\text { Non-smoker } \\
(\mathbf{n}=\mathbf{2 0})\end{array}$ & $\begin{array}{c}\text { Total } \\
(\mathbf{n}=\mathbf{3 3})\end{array}$ \\
\hline $\begin{array}{l}\text { Number of missing teeth } \\
\text { at T0 }\end{array}$ & 12 & 18 & 30 \\
$\begin{array}{l}\text { Number of tooth loss during } \\
\text { APT }\end{array}$ & 13 & 7 & 20 \\
$\begin{array}{l}\text { Number of tooth loss during } \\
\text { SPT }\end{array}$ & 1 & 2 & 3 \\
$\begin{array}{l}\text { Number of tooth loss during } \\
\text { Observation duration }\end{array}$ & 14 & 9 & 23 \\
$\begin{array}{l}\text { Mean tooth loss/person } \\
\text { Mean tooth loss/year/person }\end{array}$ & 0.19 & 0.08 & 0.13 \\
\hline
\end{tabular}

T0, baseline, 1st visit; APT, active periodontal therapy; SPT, supportive periodontal therapy.

No statistically significant difference between smoker and non$\operatorname{smoker}(p=0.062)$.

$\mathrm{APT} / \mathrm{SPT}$ 후 최종 평균 치주낭 깊이는 $4.69 \mathrm{~mm}$ 로 $2.26 \mathrm{~mm}$ 감 소하였고, 이는 통계적으로 유의한 수준이었다 $(p<0.05)$. 평균 치주낭 깊이 감소는 흡연자 군 $(1.97 \mathrm{~mm})$ 에서 비흡연자 군 $(2.78$ $\mathrm{mm})$ 보다 적었으나, 두 집단 간의 차이에 통계적 유의성은 발견 되지 않았다 $(p=0.131)$ (Table 4).

\section{고 찰}

일반적으로 급진성 치주염 연구에서 연령 기준을 35세 미만 으로 정하는 경우가 많지만[17,18], 이번 연구에서는 35세 미만 환자와 함께, 초진 검사 당시 본인이 20대에 질환이 발병된 것 을 알고 있거나 질환을 이미 진단받은 35세에서 40세 미만 환자 를 연구대상에 포함시켰다.

급진성 치주염의 유병률은 인종과 지역에 따라 매우 다양하 지만 African-American을 제외하면 대부분의 연구는 $1 \%$ 미만 을 보고하고 있다[3,4]. 이번 연구에서는 대학병원에 내원한 치 주염 환자를 대상으로 하였기 때문에 다른 연구에 비해 다소 높 은 $1.4 \%$ 의 빈도를 나타낸 것으로 추정하며 따라서 유병률 대신 빈도의 용어를 사용하였다. 8 년 동안 급진성 치주염으로 진단된 109 명의 환자 중 남성은 79 명, 여성은 30 명이었고, 성별에 따른 통계적으로 유의한 차이는 관찰되지 않았다 $(p>0.05)$. 성별에 따른 치주질환 이환의 영향은 아직까지 명확한 연관성이 증명 되지 않았는데[19], Albandar와 Rams[20]는 성별과 급진성 치 주염의 연관성을 부정한 바 있다. 급진성 치주염의 유병률 및 성 별에 따른 치주질환의 위험도를 평가하기 위해서는 향후 다양 한 환경에서 광범위한 역학 연구가 진행되어야 할 것으로 생각
Table 4. PPD during observed duration

\begin{tabular}{cccc}
\hline PPD & $\begin{array}{c}\text { Smoker } \\
(\mathbf{n}=13)\end{array}$ & $\begin{array}{c}\text { Non-smoker } \\
(\mathbf{n = 2 0})\end{array}$ & $\begin{array}{c}\text { Total } \\
(\mathbf{n}=\mathbf{3 3})\end{array}$ \\
\hline Mean PPD at T0 & $7.10 \pm 1.24$ & $6.84 \pm 1.50$ & $6.95 \pm 1.38$ \\
Mean PPD at T1 & $5.15 \pm 1.27$ & $4.37 \pm 1.10$ & $4.69 \pm 1.21$ \\
Mean PPD change & $-1.95^{\mathrm{a}}$ & $-2.47 \pm 1.56^{\mathrm{a}}$ & $-2.26 \pm 1.39^{\mathrm{a}}$ \\
\hline
\end{tabular}

Values are presented as mean \pm standard deviation $(\mathrm{mm})$.

PPD, probing pocket depth; T0, baseline, 1st visit; T1, after active periodontal therapy, supportive periodontal therapy period.

${ }^{\text {a}}$ Statistically significant difference between T0 and T1 $(p<0.05)$.

No statistically significant difference between smoker and non-smoker $(p=0.131)$.

된다.

이번 연구에서 초진 시 평균 인당 0.91 개의 치아가 상실된 상 태였다. Chung와 Jeong[21]은 평균 34.32세의 한국인 급진 성 치주염 환자에서 첫 내원 당시 평균 1.35 개의 상실치아 수를 관찰하였으나, 아울러 절망적인 예후로 평가된 치아를 상실치 아로 간주하고 이를 포함하여 치아상실률을 분석한 결과 평균 2.71 개로 두배 가량 증가한 값을 얻었다고 보고하였다. 이번 연 구결과에 대해서도 절망적인 예후를 가지는 치아를 잠정적 상 실치아로 고려할 경우 더 높은 치아 상실률이 관찰될 것으로 보 인다. 관찰기간 중 상실된 23 개의 치아 중, 상악 제 1 대구치는 3 개, 상악 제 2 대구치는 2 개로 상악 대구치의 비율이 가장 높았 다. 상악 대구치에서 관찰된 높은 치아상실률의 원인으로는 구 강위생을 위한 접근도가 낮고, 교합의 변화로 인한 간섭이 많다 는 점을 고려할 수 있다[22]. Hou 등[23]은 치아상실률에 대한 구치부 치근 형태의 영향을 제시하였으며, 해부학적 다양성이 치태 침착이 호발하는 불리한 구내 환경을 제공하여 국소적 치 주적 병소를 유발할 수 있다고 하였다. 향후 급진성 치주염 환자 에서 질환의 발병 및 진행에 대한 기여인자로써 치근 형태에 대 한 접근이 필요할 것으로 생각된다.

33 명 연구대상자에서 유지치료(SPT) 기간 중에 3개 치아가 상실되었는데, 급진성 치주염 환자가 적극적인 치주치료를 받 은 후에 유지치주치료에 정기적으로 참여할 경우 치아 상실의 빈도를 크게 감소시킬 수 있음을 의미한다고 볼 수 있다. Nibali 등[24]은 체계적 문헌고찰에서 전반적 급진성 치주염 환자는 연 간 평균 인당 0.14개(0.07-0.28 범위)의 치아를 상실한다는 결 과를 제시하였다. 이는 급진성 치주염 환자의 연간 평균 인당 상 실된 치아수가 0.13 개로 측정된 이번 연구 결과와 유사한 경향 을 보인다. Graetz 등[14] 역시 환자당 SPT 기간 중 연간 치아 상실률이 $0.14 \pm 0.18$ 개/1년이라고 보고하였다.

현재까지 다수 보고에서 흡연이 치주염의 유효한 위험인자라 는 것이 증명된 바 있으며[25], 흡연자에서 치주치료의 결과가 
더 나쁘고, 흡연이 장기 치아상실률의 증가와 연관성을 갖는다 고 보고되었다[15]. 2017년 Graetz 등[14]은 흡연과 급진성 치 주염 환자에서의 치아 상실이 높은 연관성을 가진다고 보고하 였으며, 흡연 시 치아 상실 위험이 4 배 증가한다고 밝혔다. 이번 연구에서 흡연자는 비흡연자에 비해서 초진 시 파괴 정도 평가 및 치주치료반응 평가면에서 모두 불리한 경향을 보였지만 통 계적인 유의성을 갖지는 못하였다.

한국인에서 급진성 치주염 환자의 체계적 연구는 보고된 바 가 적으므로, 이번 연구를 토대로 한국인에서 급진성 치주염의 유병률과 그로 인한 치주 조직 평균 파괴 정도를 추정하고 장기 적 치료 반응을 파악함으로써 적절한 치료계획 수립에 활용할 수 있다고 본다. 이번 연구의 경우 한 병원에서 수집된 자료이므 로 연구대상이 충분하지 못하였고, 이미 질환이 발병하여 심각 한 수준으로 심화되어 내원한 환자를 대상으로 하였다는 한계 점이 존재한다. 급진성 치주염은 사춘기에서부터 25세 이하에 서 주로 발병(onset)되어 진행하므로[17,18], 이 연령대의 큰 인 구 집단을 대상으로 한 역학연구가 필요하겠다. 다수의 기관을 포함하는 multi-center 연구도 절실하다. 추후 더 장기간에 걸 친 추적연구와 더 큰 범위의 표본집단에 대한 체계적 연구가 시 행되어야 할 것이다.

이번 연구의 한계 내에서, 급진성 치주염환자에서 종래의 통 상적 치주치료로 치아 상실의 빈도와 치주낭 깊이를 감소시킬 수 있었으며 치료 결과는 평균 5년까지 유지되었다. 3년 이상, 평균 5년 추적관찰기간 동안 치아상실률, 탐침 치주낭 깊이 변 화에서 흡연자와 비흡연자 간의 유의한 차이는 관찰되지 않았 다. 결론적으로 급진성 치주염의 조기 진단과 조기 치료가 가장 중요하며, 추후 더욱 장기간에 걸친 추적연구와 더 큰 범위의 표 본집단에 대한 체계적 연구가 시행되어야 할 것이다.

\section{ACKNOWLEDGEMENTS}

This study was supported by Wonkwang University in 2018.

\section{CONFLICT OF INTEREST}

The authors declare that they have no competing interests.

\section{ORCID}

\author{
Ye-Sol Park \\ https://orcid.org/0000-0003-0119-8795
}

\author{
Young-Mi Chung \\ https://orcid.org/0000-0001-8365-8825 \\ Seong-Nyum Jeong \\ https://orcid.org/0000-0003-4890-989X
}

\section{REFERENCES}

1. Albandar JM, Brown LJ, Löe H. Clinical features of earlyonset periodontitis. J Am Dent Assoc 1997;128:1393-1399. doi: 10.14219/jada.archive.1997.0058.

2. Tonetti MS, Mombelli A. Early-onset periodontitis. Ann Periodontol 1999;4:39-53. doi: 10.1902/annals.1999.4. 1.39 .

3. Albandar JM. Epidemiology and risk factors of periodontal diseases. Dent Clin North Am 2005;49:517-532. doi: 10.1016/j.cden.2005.03.003.

4. McLeod DE, Lainson PA, Spivey JD. The effectiveness of periodontal treatment as measured by tooth loss. J Am Dent Assoc 1997;128:316-324. doi: 10.14219/jada. archive.1997.0195.

5. Albandar JM, Tinoco EM. Global epidemiology of periodontal diseases in children and young persons. Periodontol 2000 2002;29:153-176. doi: 10.1034/j.16000757.2002.290108.x.

6. Meng H, Xu L, Li Q, Han J, Zhao Y. Determinants of host susceptibility in aggressive periodontitis. Periodontol 2000 2007;43:133-159. doi: 10.1111/j.1600-0757.2006.00204.x.

7. Leem SH, Chung CP, Son SH. Epidemiological, clinical and microbiological studies of juvenile periodontitis at age 15 17 years. J Korean Acad Periodontol 1987;1:358.

8. Susin C, Albandar JM. Aggressive periodontitis in an urban population in southern Brazil. J Periodontol 2005;76:468475. doi: 10.1902/jop.2005.76.3.468.

9. Kim HK. Etiology, treatment, and prognosis about aggressive periodontitis [Thesis]. Seoul: Seoul National University; 2014.

10. Mombelli A, Casagni F, Madianos PN. Can presence or absence of periodontal pathogens distinguish between subjects with chronic and aggressive periodontitis? A systematic review. J Clin Periodontol 2002;29 Suppl 3:1021; discussion 37-8. doi: 10.1034/j.1600-051X.29.s3.1.x.

11. Buchmann R, Nunn ME, Van Dyke TE, Lange DE. Aggressive periodontitis: 5-year follow-up of treatment. J Periodontol 2002;73:675-683. doi: 10.1902/jop.2002.73.6.675.

12. Miller KA, Branco-de-Almeida LS, Wolf S, Hovencamp N, Treloar T, Harrison P, Aukhil I, Gong Y, Shaddox LM. Long-term clinical response to treatment and maintenance of localized aggressive periodontitis: a cohort study. J Clin Periodontol 2017;44:158-168. doi: 10.1111/jcpe.12640.

13. Rabelo CC, Feres M, Gonçalves C, Figueiredo LC, Faveri M, Tu YK, Chambrone L. Systemic antibiotics in the 
treatment of aggressive periodontitis. A systematic review and a Bayesian Network meta-analysis. J Clin Periodontol 2015;42:647-657. doi: 10.1111/jcpe.12427.

14. Graetz C, Sälzer S, Plaumann A, Schlattmann P, Kahl M, Springer C, Dörfer C, Schwendicke F. Tooth loss in generalized aggressive periodontitis: prognostic factors after 17 years of supportive periodontal treatment. J Clin Periodontol 2017;44:612-619. doi: 10.1111/jcpe.12725.

15. Díaz-Faes L, Guerrero A, Magán-Fernández A, Bravo M, Mesa F. Tooth loss and alveolar bone crest loss during supportive periodontal therapy in patients with generalized aggressive periodontitis: retrospective study with followup of 8 to 15 years. J Clin Periodontol 2016;43:1109-1115. doi: $10.1111 /$ jcpe. 12596.

16. American Academy of Periodontology task force report on the update to the 1999 classification of periodontal diseases and conditions. J Periodontol 2015;86:835-838.

17. Ranney RR. Classification of periodontal diseases. Periodontol 2000 1993;2:13-25. doi: 10.1111/j.1600-0757. 1993.tb00216.x.

18. Suzuki JB, Charon JA. Current classification of periodontal diseases. J Parodontol 1989;8:31-51.

19. Hermann P, Gera I, Borbély J, Fejérdy P, Madléna M.
Periodontal health of an adult population in Hungary: findings of a national survey. J Clin Periodontol 2009;36: 449-457. doi: 10.1111/j.1600-051X.2009.01395.x.

20. Albandar JM, Rams TE. Risk factors for periodontitis in children and young persons. Periodontol 2000 2002;29:207222. doi: 10.1034/j.1600-0757.2002.290110.x.

21. Chung YM, Jeong SN. The evaluation of tooth loss and periodontal attachment loss in aggressive periodontitis patients. Oral Biol Res 2013;37:14-19.

22. Cho CM, You HK, Jeong SN. The clinical assessment of aggressive periodontitis patients. J Periodontal Implant Sci 2011;41:143-148. doi: 10.5051/jpis.2011.41.3.143.

23. Hou GL, Tsai CC, Huang JS. Relationship between molar root fusion and localized periodontitis. J Periodontol 1997; 68:313-319. doi: 10.1902/jop.1997.68.4.313.

24. Nibali L, Farias BC, Vajgel A, Tu YK, Donos N. Tooth loss in aggressive periodontitis: a systematic review. J Dent Res 2013;92:868-875. doi: 10.1177/0022034513501878.

25. Palmer RM, Wilson RF, Hasan AS, Scott DA. Mechanisms of action of environmental factors--tobacco smoking. J Clin Periodontol 2005;32 Suppl 6:180-195. doi: 10.1111/ j.1600-051X.2005.00786.x. 